http://doi.org/10.35784/iapgos.921

\title{
APPLICATION OF HURST INDICATOR TO CHOOSE AN ALGORITHM FOR RESOURCE CONTROL OF A TELECOMMUNICATION NETWORK
}

\author{
Anton Vrublevskiy, Ivan Lesovoy, Gennadij Pylypenko \\ Odessa National Academy of Telecommunication named after O.S. Popov, Department of Telecommunications Systems, Odessa, Ukraine
}

Abstract. It has been shown that fuzzy integrals (Sugeno and Shocke) have special properties and are suitable for a fuzzy system for managing the resources of a telecommunication network. The form of choosing a method for calculating the Hurst coefficient in a fuzzy control system for telecommunication network resources is proposed.

Keywords: traffic, Hurst coefficient, membership function, fuzzy integral, fuzzy measure

\section{ZASTOSOWANIE WSKAŹNIKA HURSTA W SIECI TELEKOMUNIKACYJNEJ DLA WYBORU ALGORYTMU STEROWANIA}

Streszczenie. Wykazano, że całki rozmyte (Sugeno i Shock) maja szczególne właściwości i sa odpowiednie dla systemu rozmytego do zarzadzania zasobami sieci telekomunikacyjnej. Zaproponowano formę wyboru metody obliczania wspótczynnika Hursta w systemie sterowania rozmytego dla zasobów sieci telekomunikacyjnych.

Słowa kluczowe: ruch, współczynnik Hursta, funkcja przynależności, całka rozmyta, miara rozmyta

\section{Introduction}

Functioning of telecommunication network is characterized by a number of indicators, such as: parameters of the quality of network operation (packet delay, jitter, packet loss ratio, etc.), and economic parameters (capital costs, operating costs). To ensure functioning of telecommunication network with specified parameters, it is necessary to manage the resources of telecommunication network. A system for managing resources of a telecommunication network means a set of software and hardware that ensures the operation of a network with specified parameters: time delay, packet loss rate, which can be associated with a certain type of traffic on the channel, and with the network load as a whole.

One of the important tasks of ensuring a given quality of service is the control of telecommunication network resources. With increasing traffic intensity TCP overload prevention mechanisms and tools built into the operating systems do not work effectively. A packet is dropped only in the event of actual buffer overflow. This reduces the current traffic, but subsequently leads to a wave-like change in the queue length and causes network overload, which increases jitter and reduces the network bandwidth.

The research in the field of traffic analysis of modern networks with packet switching indicates that data traffic, in contrast to a classical representation of traffic by a Poisson stream, it manifests variability in a wide range of time scales (presents the property of self-similarity).

The algorithms for processing traffic created to work with the simplest threads are not enough effective for streams that have the property of self-similarity.

Thus, a need is required to improve methods for operational resource allocation of the data link multi-service network based on the prediction of the Hurst coefficient and methods for assessing its probabilistic time characteristics in the presence of selfsimilarity properties of the incoming load.

This will ensure increased efficiency traffic processing in terms of improving indicators such as values of delay, packet loss, and coefficient channel use.

\section{Fuzzy traffic management system}

The resources of telecommunication network are managed under the conditions of changing the parameters of transmission paths, loading buffers, characteristics of load flows, time intervals, etc. over a wide range. The main reasons for these changes are the constant impact of internal and external factors: the variation in the parameters of the equipment of telecommunication systems, information distribution systems, changes in the conditions of operation of the telecommunication network, etc. This creates multi-criteria uncertainty, which makes it impossible to correctly solve the problem of optimal management of telecommunication network resources without taking into account the interests of stakeholders.

The important factor in managing the resources of telecommunication network is a degree of congestion of output interfaces of routers, which determines expediency of dropping a packet or directing it over a longer route on which the buffers are not so loaded. In the process of managing resources, it is advisable to take into account not only the distance, but also the load dynamics of output buffer of the drive corresponding to the interface and a number of other factors.

Usually, when studying a telecommunication network, to establish the connection between the total (full) assessment of an object and the partial estimates of the constituent elements, the object under study is decomposed into its constituent elements and a linear mathematical model is applied:

$$
z=\sum_{i=1}^{n} a_{i} h\left(x_{i}\right),
$$

where $U=\left\{x_{1}, x_{2}, \ldots, x_{\mathrm{n}}\right\}$ is the set of information elements, function $h: U \rightarrow[0,1]$ represents measurement results of information elements, and $a_{i}$ are constants expressing the coefficients of importance of the corresponding information elements. The linear criterion is a weighted sum of particular criteria.

However, a different mathematical model is needed for the tasks of managing the resources of a telecommunication network in fuzzy conditions. The fuzzy Sugeno integral $[3,11]$ can be used as a mathematical model.

The control algorithm based on fuzzy logic allows taking into account the influence of many factors when managing the resources of a telecommunication network. The main advantage of fuzzy regulators for a telecommunication network resource management system is the use of qualitative information, which cannot be formalized when traditional management methods are implemented, the low sensitivity of fuzzy regulators to disturbances in a certain range and better characteristics compared to classical regulators.

The resource management in a telecommunication network is carried out with fuzzy parameters, in real time. Given convenience of formalizing information about procedures and conditions for their use, when describing the knowledge, it is advisable to use a set of fuzzy production rules. Each fuzzy production rule allows putting a certain action in accordance with the current situation. 
The main difficulty in creating a resource management system for a telecommunication network based on fuzzy logic is that changing the parameters of a telecommunication network (control object) entails modifying the control rules with their subsequent iterative adjustment, which takes time.

There is a problem of ensuring the optimal characteristics of telecommunication network resource management system and, in particular, their stability and dynamics. In order to dynamically manage the resources of a telecommunication network, special technical tools are needed that adapt to constantly changing conditions, that is, adaptive control systems. The main goal of adaptation or adaptive management of telecommunication network resources is to improve the quality of service in the changing conditions of its operation.

A promising direction in the development of fuzzy regulators is the creation of adaptive and self-organizing fuzzy regulators. In the process of managing the resources of a telecommunications network, a fuzzy adaptive controller, based on traffic prediction, status of information distribution devices and transmission paths, determines the values of parameters necessary to stabilize the quality of service at a given level.

In order to dynamically control the resources of telecommunication network, special technical tools are required that adapt to changing conditions, that is, adaptive control systems. The main purpose of adaptation or adaptive management of telecommunication network resources is to improve the quality of service in terms of its operation.

The advantage of fuzzy regulators for a telecommunication network resource management system is the use of qualitative information, which cannot be formalized when traditional management methods are implemented, the low sensitivity of fuzzy regulators to disturbances in a certain range and better characteristics compared to classical regulators. In the process of managing the resources of telecommunication network, a fuzzy adaptive controller, based on the prediction of the status of information distribution devices and transmission paths, determines the values of parameters necessary to stabilize the quality of service at a given level. The main difficulty in creating fuzzy regulators is that changing the parameters of the telecommunication network (control object) entails modifying the control rules with their subsequent iterative adjustment, which takes time.

Self-similarity of traffic is manifested in the fact that with the increase in aggregation interval, the traffic structure of lower levels of hierarchy is preserved and, as a rule, depends on efficiency of the use of transmission paths $[2,4,5,6,8,10,12]$. The presence of self-similarity or scale invariance allows forecasting, by analyzing the traffic over a relatively short period of time, to predict its behavior over longer time intervals [7]. These forecasts can be used to select the method of managing the resources of a telecommunication network in the presence of traffic surges for its efficient operation.

Hurst index $H$, which is a measure of self-similarity of the stochastic process, allows estimating the traffic self-similarity, takes values from 0 to 1 and allows establishing the difference between random processes with independent increments (at $H=0.5$ ), with statistically dependent values, manifestation. There is a so-called persistent (supporting) behavior $(H>0.5)$, and with statistically dependent values that show anti-persistent behavior $(H<0.5)$.

There are several methods used to determine the Hurst index: analysis of R/S statistics, analysis of variance changes, first analysis, analysis of the auto-correlation function, Whittle estimation, analysis based on the wavelet function, and analysis of the dispersion index for samples. The value of Hurst coefficient can be determined using the methods:

- theory of probability;

statistical theory;

based on the theory of fuzzy sets (fuzzy measures).
It should be noted that when studying the same experimental traffic data, the value of Hurst index depends on the estimation method, sample size, the number of load sources, etc.

To calculate the Hurst coefficient by a probabilistic method, it is necessary to know the density of its distribution in the $H_{E}$ region. In order to determine the value of Hurst coefficient by a statistical method, with an acceptable probability, a sufficiently large sample is necessary. As a rule, in traffic control problems, the law of distribution of the Hurst index in a region is not defined, and a full sample of data, that is, complete information about the behavior, its value in a given region is also absent. Therefore, in a fuzzy system for managing the resources of a telecommunication network, an assessment of the value of Hurst index is advisable to be carried out using the theory of fuzzy sets.

For each current value of the input variable, the degree of belonging (truth value) to these terms (fuzzy sets) characterizing a specific linguistic variable is determined. Each of these fuzzy subsets consists of elements along with their degrees of belonging. The number of terms $\mathrm{j}$ for each linguistic variable is desirable to choose the same.

The graphs of membership functions (MF) of fuzzy sets may have a different shape depending on the preferences and developer experience. In the tasks of managing the resources of a telecommunication network based on fuzzy logic, it is advisable to use simple linear and triangular membership functions, which simplify the calculations.

We write the membership function in the form

$$
\mu(X)=\sum_{i} \mu_{i} / x_{i}
$$

where: $\sum$ - the union of elements; $\mu_{i}$ - the degree of belonging of the element $x_{i}$ to the set.

If the distribution of the fuzzy density of weights of these values $g\left(H_{j}\right), H_{j} \in H_{E}$ is determined a priori, by means of an examination, it is possible to determine the expected value of the Hurst coefficient $H_{j}$ from the $H_{E}$ region from the experimental results using the fuzzy integral.

\section{Fuzzy integral}

Fuzzy integral is a non-linear functional. By analogy with the mathematical expectation of probability theory, a fuzzy integral is sometimes called a fuzzy mathematical expectation. The fuzzy Sugeno integral of the function $h$ on the set $U$ by a fuzzy measure $g$ is determined from the expression

$$
\int h \circ g=\sup \left(a \wedge g\left(F_{a}\right)\right), F_{a}=\{x \in U: h(x) \geq a\}, a \in[0,1]
$$

where the symbol $\int-$ denotes a fuzzy integral, $\circ-$ is the sign of the composition.

Let the integration be performed on the set $A \subseteq U$, then the fuzzy integral describes the expression

$$
\int_{A} h(x) \circ g=\sup \left(a \wedge g\left(A \cap F_{a}\right)\right), a \in[0,1]
$$

For a set of information elements $U=\left\{x_{1}, x_{2}, \ldots x_{n}\right\}$, fuzzy integral

$$
\begin{gathered}
\left(h\left(x_{i}\right) \wedge g\left(E_{i}\right)\right), E_{i}=\left\{x_{i}, \ldots, x_{n}\right\}, \\
a_{i}=\max \left\{a_{i}\right\},
\end{gathered}
$$

if the condition is met $h\left(x_{i}\right) \leq \ldots \leq h\left(x_{n}\right)$, and

$$
\left(h\left(x_{i}\right) \wedge g\left(E_{i}\right)\right), \quad E_{i}=\left\{x_{1}, \ldots, x_{i}\right\} \text { if a } h\left(x_{1}\right) \geq \ldots \geq h\left(x_{n}\right) .
$$

The fuzzy integral of the function $h$ over a fuzzy measure $g$ is a general estimate in the form of a non-linear convolution of the partial estimates of information elements, but it does not exclude the possibility of information elements interconnection. 
If the posteriori membership function of a region is determined, then the most expected value of $H_{j}$ is determined by the expression [3]

$$
H=\arg \int_{H_{\ni}} h\left(H_{j}\right) \circ g\left(F_{j}\right),
$$

where $\int-$ is the sign of a fuzzy integral; 0 - sign of the composition; $h\left(H_{j}\right)$ is the function of the membership function ordered in descending powers $\mu\left(H_{j}\right) ; g\left(F_{j}\right)$ is a fuzzy measure of a set

$$
F_{j}=\left\langle H_{j 1}, H_{j 2}, \ldots, H_{j i}\right\rangle .
$$

The procedure for calculating a fuzzy integral for $U$ which is a finite set $U=\left\{x_{1}, \ldots x_{\mathrm{n}}\right\}$ is laid down in its definition:

$$
\begin{gathered}
\left(h\left(x_{i}\right) \wedge g\left(E_{i}\right)\right), \\
E_{i}=\left\{x_{i}, x_{i+1},, x_{n}\right\}, E_{1} \supset E_{2} \supset \ldots E_{n}, E_{1}=U . \\
\int h(x) \circ g=h\left(x_{i}\right) \wedge g\left(E_{j}\right),
\end{gathered}
$$

then and only then ever

$$
h\left(x_{j-1}\right) \leq g\left(E_{j}\right) \leq h\left(x_{j}\right) .
$$

or

$$
g\left(E_{j+1}\right) \leq h\left(x_{j}\right) \leq g\left(E_{j}\right) .
$$

Thus, the value of a fuzzy integral can be obtained without calculating

$$
h\left(x_{i}\right) \wedge g\left(E_{i}\right)
$$

for all $i$.

Let as a result of traffic analysis using the R/S statistics estimation method, the value of the Hearst coefficient $H_{1}=0.84$ is obtained; method of estimating the spectral functions $H_{2}=0.93$ and the method of estimating the correlation coefficient $H_{3}=0.65$. In order to determine the most possible value of the Hurst coefficient, we calculate the fuzzy integral.

Let the following membership function be known, written according to:

$$
\mu\left(H_{j}\right)=0.84 / 0.4+0.93 / 0.9+0.65 / 0.8
$$

Ordered by decreasing powers membership function

$$
h\left(H_{j}\right): h\left(H_{2}\right)=0.9 ; h\left(H_{3}\right)=0.8 ; h\left(H_{1}\right)=0.4 .
$$

Fuzzy measures:

$$
g\left(F_{1}\right)=0.5 ; g\left(F_{2}\right)=0.81 ; g\left(F_{3}\right)=0.75 .
$$

To this end, the ordering of of the function $\mathrm{h}$ value, we make the change of variables, taking

$$
y_{1}=H_{1}, y_{2}=H_{3}, y_{3}=H_{2} .
$$

Then, $h\left(y_{1}\right)<h\left(y_{2}\right)<h\left(y_{3}\right)$ and according to the definition of a fuzzy integral, we calculate

$$
\begin{gathered}
h\left(y_{i}\right) \wedge g\left(E_{i}\right), E_{i}=\left\{y_{1}, \ldots, y_{3}\right\}, i=1,2,3 . \\
\text { when } i=1, h\left(y_{1}\right) \wedge g\left(E_{1}\right)=0.4 \wedge 1.0=0.4 . \\
\text { when } i=2, h\left(y_{2}\right) \wedge g\left(E_{2}\right)=0.8 \wedge 0.81=0.8 . \\
\text { when } i=3, h\left(y_{3}\right) \wedge g\left(E_{3}\right)=0.9 \wedge 0.75=0.75 .
\end{gathered}
$$

Consequently,

$$
\left(h\left(y_{i}\right) \wedge g\left(E_{i}\right)\right)=\max (0.4 ; 0.8 ; 0.75)=0.8
$$

Thus, the most possible value of the Hurst coefficient is 0.65 with an expected measure of 0.81 . Therefore, the fuzzy adaptation system will perform the calculation of the Hurst coefficient by the method of estimating the correlation coefficient.

In order to determine the most expected value of $H_{j}$ for continuous functions, according to [1], it is possible to present it graphically (Fig. 1).

The solution of the fuzzy integral allows us to determine [1]:

the expected fuzzy measure of the set NOT;

- the most likely value of the Hurst coefficient in the area is NOT with its fuzzy estimate;

- coefficient value (the boundary of the region is NOT into two sub-regions $H_{1}$ and $H_{2}$ ).

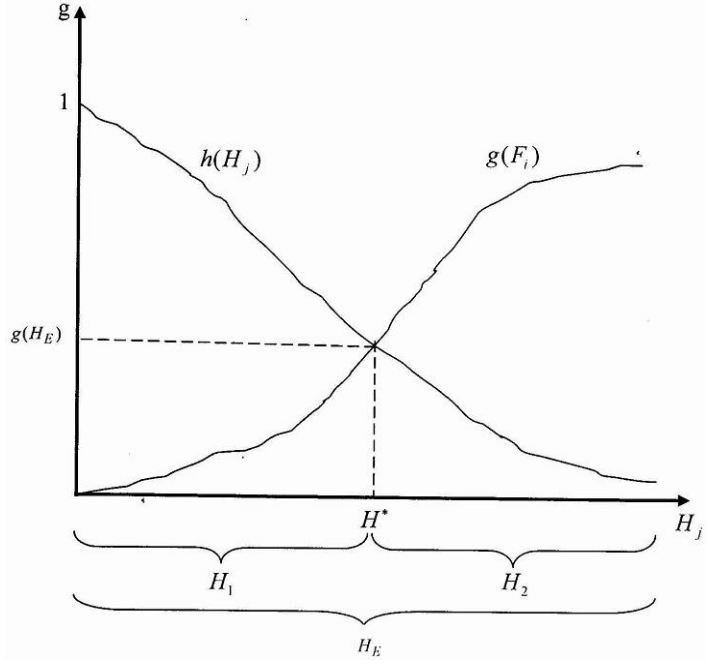

Fig. 1. Graphic solution of a fuzzy integral

Knowing this limit allows you to specify the most likely value of the Hurst coefficient obtained from the results of the experiment.

For a graphical solution of a fuzzy integral, we construct a graph applying the traffic analysis data using the method of estimating R/S statistics; the value of the Hurst coefficient $H_{1}=0.84$; method of estimating the spectral functions $H_{2}=0.93$ and the method of estimating the correlation coefficient $H_{3}=0.65$.

Let the following membership function be known, written according to:

$$
\mu\left(H_{j}\right)=0.84 / 0.4+0.93 / 0.9+0.65 / 0.8 \text {. }
$$

Ordered by decreasing powers membership function

$$
h\left(H_{j}\right): h\left(H_{2}\right)=0.9 ; h\left(H_{3}\right)=0.8 ; h\left(H_{1}\right)=0.4 .
$$

Fuzzy measures:

$$
g\left(F_{1}\right)=0.8 ; g\left(F_{2}\right)=0.5 ; g\left(F_{3}\right)=0.75 .
$$

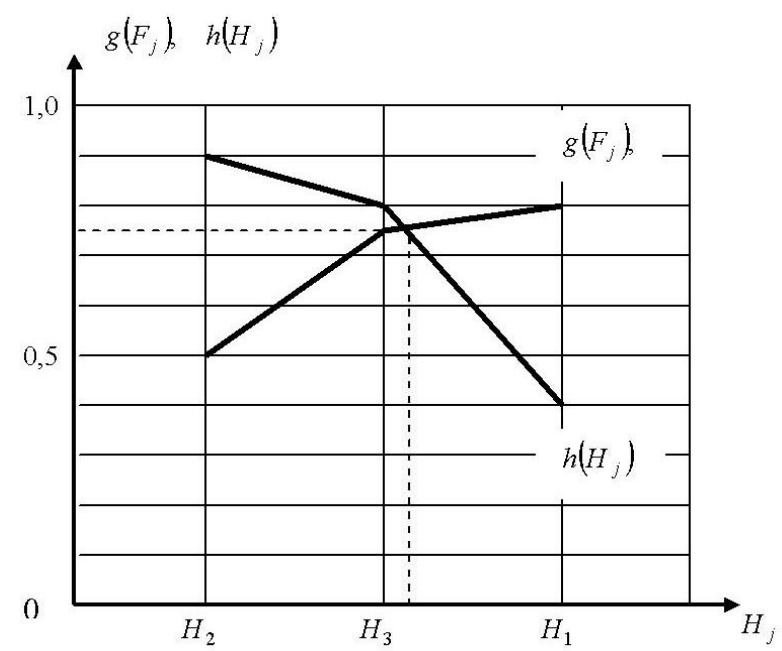

Fig. 2. An example of a graphical determination of the most possible value of $H$ using a fuzzy integral

Many properties of telecommunication networks are fuzzy, which makes fuzzy methods applicable for monitoring their parameters. Fuzzy analysis is more efficient than traditional data processing methods, which are usually inaccurate and ambiguous. Fuzzy methods are able to classify model errors in a nondichotomous way, similar to the way a person processes inaccurate information. The concepts of fuzzy measure and fuzzy integral are taken from the classical theory of sets, the theory of fuzzy sets and the theory of measure.

The important properties of fuzzy measures and fuzzy integrals are the ability to reflect the importance of criteria and to represent certain interactions between the criteria. Fuzzy measures 
and fuzzy integrals may reflect the importance of criteria and represent certain interactions between the criteria. These properties make fuzzy measures and fuzzy integrals the most rational for choosing the function and mechanisms of state and control of a telecommunication network.

Fuzzy integrals (Sugeno and Choke) are suitable for managing the resources of a telecommunication network [10]. The use of a fuzzy integral is constrained by the difficulty of defining a fuzzy measure.

\section{Conclusion}

The presence of self-similarity or scale invariance allows forecasting, by analyzing traffic over a relatively short period of time, to predict its behaviour over longer time intervals. These forecasts can be used to select the method for managing the resources of a telecommunication network in the presence of traffic surges to ensure its efficient operation.

The application of the Hurst index in order to select the algorithm for managing the resources of a telecommunication network requires the complex use of fractal analysis methods in the study of time series of small length.

The fuzzy analysis is more efficient than traditional data process-sing methods, which are generally inaccurate and ambiguous. Fuzzy methods allow us to classify model errors in a nondichotonous way, which is similar to the way human information is processed.

Fuzzy measures and fuzzy integrals provide an insight into the importance of each parameter and some of the relationships between parameters. These properties allow the fuzzy measure and the theory of fuzzy integrals to apply in adaptive systems for managing resources of a telecommunication network based on fuzzy logic.

\section{References}

[1] Bychkov Ye. D.: Prilozheniye teorii nechetkikh (FUZZY) mnozhestv v matematicheskikh modelyakh sistem svyazi. Izd-vo Omskoy Gos. Med. Akademii, Omsk 2000.

[2] Dang T. D., Sonkoly B., Molnar S.: Fractal Analysis and Modelling of VoIP Traffic. NETWORKS-2004. Vienna. Austria. 2004, 95-104.

[3] Dubois D., Prad H.: Fuzzy Sets and Systems: Theory and applications. Acad. Press, New York 1980.

[4] Ghaderi M.: On the Relevance of Self-Similarity in Network Traffic Prediction. School of Computer Science, University of Waterloo, Waterloo 2003.

[5] Ilnickis S.: Research of the Network Server in Self-Similar Traffic Environment Scientific proceedings of Riga Tecnical University Telecommunication and Electronics. Computer Science 1/2004, 78-81.

[6] Karasaridis A., Hatzinakos D.: Network Heavy Traffic Modeling Using a-stable Self-Smilar Process. IEEE Transactin on Communications 49(7)/2001, 1203 1214
[7] Neyman V. I.: Novoye napravleniye v teorii teletrafika. Elektrosvyaz' 7/1998, $27-29$

[8] Osin A. V.: Vliyaniye samopodobnosti rechevogo trafika na kachestvo obsluzhivaniya v telekommunikatsionnykh setyakh. PhD thesis, Moscow 2005.

[9] Pospelov D. A.: Nechetkiye mnozhestva v modelyakh upravleniya i iskusstvennogo intellekta. Nauka, Moscow 1986.

[10] Shelukhin O. I. (red.): Fraktal'nyye protsessy v telekommunikatsiyakh. Radiotekhnika, Moscow 2003.

[11] Sugeno M.: Fuzzy measures and fuzzy integrals: a survey. Fuzzy automata and decision processes. North-Holland Publishning Company, Amsterdam 1977 $89-102$.

[12] Tsybakov B. S., Georganas N. D.: Self-Similar Processes in Communications Networks. IEEE Trans. on Information Theory 44(5)/1998, 1713-1725.

\begin{abstract}
M.Sc. Anton Vrublevskiy
e-mail: vrublevskiyar@gmail.com

Vrublevskiy Anton Romanovych postgraduate student of the department of Telecommunication Systems, Institute of Information and Communication Technologies and Computer Engineering of Odessa National Academy of Telecommunications, the name of A.S. Popov. Author of 11 scientific works. Research interests is packet network traffic management on the fuzzy logic base.
\end{abstract}

http://orcid.org/0000-0002-6488-3418

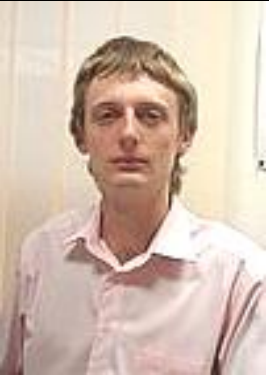

D.Sc. Ivan Lesovoy

e-mail: ur5fo55@gmail.com

Lesovoy Ivan Pavlovich doctor of Technical Sciences (2005), Professor (2008). Professor of the Department of Telecommunication Systems, Institute of Information and Communication Technologies and Computer Engineering of Odessa National Academy of Telecommunications the name of A.S. Popov. Author of more than 100 scientific works, including 10 monographs, 5 textbooks. Research interests: fuzzy logic in telecommunications, digital processing and signal generation in telecommunication systems.

http://orcid.org/0000-0002-3807-2099

\section{M.Sc. Gennadij Pylypenko}

e-mail: gvpilipenko@gmail.com

Pylypenko Gennadij Viktorovych postgraduate student of the department of Telecommunication Systems, Institute of Information and Communication Technologies and Computer Engineering of Odessa National Academy of Telecommunications, the name of A.S. Popov. Author of 9 scientific works. Research interests is packet network traffic management on the fuzzy logic base.

http://orcid.org/0000-0002-8635-9019

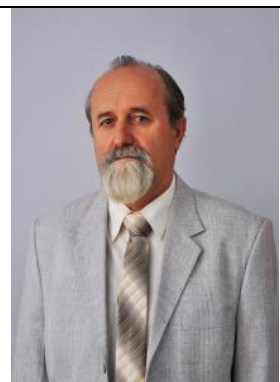

otrzymano/received: 15.11 .2019

przyjęto do druku/accepted: 15.02 .2020 